\title{
A New Approach for Machine Gauge \& Production Calculation of Various Kinds of Rib and Interlock Knitted Fabric Structure
}

\author{
Ripon Kumar Prasad \\ Department of AMT, BGMEA University of Fashion \& Technology, Dhaka, Bangladesh \\ Email: srkprasadte10@gmail.com
}

Received 24 January 2016; accepted 9 May 2016; published 12 May 2016

Copyright @ 2016 by author and Scientific Research Publishing Inc.

This work is licensed under the Creative Commons Attribution International License (CC BY). http://creativecommons.org/licenses/by/4.0/

c) (i) Open Access

\begin{abstract}
Various types of rib and interlock fabrics found in the market depend on their structure such as 1 $\times 1 \mathrm{rib}, 2 \times 1 \mathrm{rib}, 2 \times 2 \mathrm{rib}, 3 \times 1 \mathrm{rib}, 3 \times 2 \mathrm{rib}, 4 \times 1 \mathrm{rib}, 4 \times 4$ rib and $1 \times 1$ interlock, $2 \times 2$ interlock etc. These all types of fabric can be possible to knit in circular knitting machine after machine setting. When these fabrics are knit on the machine, some needles are needed to drop or withdrawn from needle groove according to their design such as $1 \times 1,2 \times 1,2 \times 2$ etc. Due to needle dropping or withdrawing production per hour will changed as production per hour directly depends on the No. of active needle. No. of needle or active needle depends on machine gauge. This paper gives a new approach for machine gauge which is somewhat different from other thinking. This paper also shows the production calculation formula with their machine setting for various rib and interlock fabric with their derivation. By this paper, one can easily understood about machine gauge and calculated production of any type of rib and interlock knitted structure. Complexity of calculating production can be reduced by this paper.
\end{abstract}

\section{Keywords}

Machine Gauge, Production per Hour, Formula, Rib, Interlock, Fabric

\section{Introduction}

Knitting is the second most popular technique of fabric or garment formation by inter-looping one or one set of yarns. Continuous length of yarn is converted into vertically intermeshed loops either by hand or by machine in knitted fabric [1]. Knitted fabric can be classified into two main categories such as warp knitted fabric and weft knitted fabric. Due to higher production, lower cost and easy installment demand of weft knitted fabric increas- 
ing day by day. For the weft knitted fabric production, two main knitting machines are used such as flat bed knitting machine and circular knitting machine. But in worldwide, circular knitting machines are widely used because higher production and higher quality of fabric can be achieved [2]. On the basis of knitted stitches per minute against the capital cost of the machine, circular garment-length machines are generally more productive than flat bed machines for cut and sew knitwear. Prior to computer controls, the price/performance ratio was 1:3 in favor of body-width circular machines [3]. The term circular covers all those weft knitted machines whose needle beds are arranged in circular cylinder and dials or only in cylinder including latch, spring bearded and very occasionally compound needle machinery, producing a wide range of fabric structures, garments, hosiery and other articles in a variety of diameters and machine gauges [2]. There are four weft knitted structure named single jersey, rib, interlock and purl. It is possible to produce all of these knit fabrics by circular machine after some changes. Circular machines are mainly single cylinder type for single jersey fabric, cylinder and dial type for rib and interlock fabrics and double cylinder types for purl fabrics [3]. Single jersey is the simplest structure among four basic wefts knitted structure. Due to machine complexity, higher cost and lower demand uses of purl structure decreases day by day. On the other hand, uses of rib and interlock structure increase day by day. Many types of rib structures can be produced according to the arrangement of needles in the cylinder and dial bed [2], such as $1 \times 1,2 \times 1,2 \times 2$ etc. Also interlock structures can be produced in many types such as $1 \times 1,2 \times 2,3 \times$ 3 etc. Production of knitted structure is totally mathematical based depends on various factors. Machine gauge is one of the important factors among them. It is very important for the knitter to calculate the productivity of a machine in order to be able to schedule production and specify the delivery dates to the customer [4]. It is very easy to calculate the production of single jersey and $1 \times 1$ rib fabrics. There are some problems associated due to machine setting when knitters going to calculate the production of other rib and interlock structures. This paper is going to show the production calculation formula for various rib and interlock structure.

\section{Related Term}

Machine gauge: The machine gauge of knitting machines is a measure expressing the number of needles per a unit (normally 1 inch) of the needle bed width or circumference [2] [3]. Machine gauge is defined in various units (systems) in various countries. Definition of gauge also depends on the types of knitting machines. Most popularly, it is defined in English system as the number of needles per inch [1].

Machine diameter: The diameter of knitting machines is measured at the bottoms of the two opposite needle grooves in a cylinder or at the top of the two opposite needles in a circular bar and is usually expressed in inches [2].

Number of feed system or feeder: On the circumference of a circular knitting machine up to 120 knitting cam sets can be mounted, each cam set fed with a separate yarn. This results in obtaining 120 knitted loop courses in one machine revolution [2].

Stitch length: The length of yarn knitted into one stitch in a weft knitted fabric [2].

\section{Materials \& Method}

Rib circular latch needle machine: There are two circular needle beds on this type knitting machine such as cylinder bed and dial bed. Latch needle cylinder dial revolve through the stationary cam system. In this machine, there is one set of needles on the circumference of a vertical cylinder and a second set of needles, arranged perpendicular to the first set and mounted on a horizontal dial [2]. In rib gating each cylinder needle is neighbored by a dial needle and they are offset with respect to each other such that when both sets move forward to catch yarn, each cylinder needle passes through the gap between two neighboring dial needles [5]. A 30 gauge circular knitting machine is consider suitable for the production of $1 \times 1$ rib fabric and approaching the machine gauge newly.

Interlock circular latch needle machine: In case of conventional interlock machine, both the needle bed contains one short butt and one long butt needles once after another. But in modern machine the needles are of the same length [2]. With an interlock gating the two interlocking ribs are knitted with a phase difference by two neighboring feeders [5]. In interlock gating, the needle in two beds must be exactly opposite to each other so only one of the two can knit at any feeder [3].

Machine setting for $2 \times 1$ rib machine: A $1 \times 1$ rib gating in which each cylinder needle is neighbored by a dial needle and they are offset with respect to each other such that when both sets move forward to catch yarn, 
each cylinder needle passes through the gap between two neighboring dial needles. When this $1 \times 1$ rib machine is converted for $2 \times 1$ rib fabric, one needle is dropped after every two needles from both of the needle bed. Needle can be dropped by using miss cam or withdrawn of needle from the needle groove.

Machine setting for $2 \times 2$ rib fabric: When $1 \times 1$ rib machines is converted for $2 \times 2$ rib machine, two needles are dropped after every two needles from both of the needle bed.

Machine setting for $3 \times 2$ rib fabric: For $3 \times 2$ rib fabric machine setting, two needles are dropped after every three needle from both of the needle bed.

Machine setting for $\mathbf{3} \times \mathbf{3}$ rib fabric: When $1 \times 1$ rib machines is converted into $3 \times 3$ rib machines, three needles are dropped after three needle from both of the needle bed.

Machine setting for $\mathbf{4} \times \mathbf{1}$ rib fabric: For $4 \times 1$ rib fabric machines, one needle is dropped after every four needle from both of the needle bed.

Machine setting for $\mathbf{4} \times \mathbf{4}$ rib fabric: For $4 \times 4$ rib fabric machines, four needles are dropped after every four needle from both cylinder and dial bed.

Machine setting for $\boldsymbol{x} \times \boldsymbol{y}$ rib fabric: Here $x$ denoted the no. of face loop and $y$ denoted the no. of back loop. $y$ no. of needles is needed to dropped or withdrawn after $x$ no. of needles for this type of fabric.

Machine setting for $1 \times 1$ interlock fabric: In this case, needles of both beds operate consecutively and then after a certain delay on the passive needle bed. The active needle bed is that which receives the yarn for forming loops from the yarn carrier. That means the time of knitting operation fifty percent needles are active and rest fifty percent are inactive. In next knitting cycle previously inactive needles are active and previously actives are inactive.

Machine setting for $2 \times 2$ interlock fabric: When $1 \times 1$ interlock machines are converted for $2 \times 2$ interlock machines, two needles are dropped after every two needle. Needles can be dropped by using miss cam or withdrawn of needle from the needle groove. $2 \times 2$ interlock machine runs by maintaining same principle of $1 \times 1$ interlock machines.

Machine setting for $\boldsymbol{x} \times \boldsymbol{y}$ interlock fabric: Here $x$ and $y$ denoted no. of face and back loop respectively. When any interlock machine converted for this type of structure $y$ no. of needles are needed to dropped or withdrawn after $x$ No. of needle. Operating principle is same as any other interlock fabric.

\section{Results \& Discussion}

New Approach for Machine Gauge: Appropriately machine gauge is the total number of needle grooves of tricks per unit length (normally 1 inch). It can be also defined as the capacity of carrying total no. of number of needles per inch. It is somewhat same to the old concept. For an example, A 30 gauge circular knitting machine is running with $1 \times 1$ rib fabric machine setting. That means the machine has 30 needles in 1 inch and also 30 needle grooves. When this machine is converted for $2 \times 1$ rib fabric, it has been needed to drop or withdrawn 1 needle after every 2 needle from both of the needle bed. In this case, no. of needle is 20 in 1 inch length where needle grooves remains 30 . But the machine is 30 gauges for all time and for all of the structures.

Production Calculation: If all needle grooves are filled by needle,

$$
\begin{aligned}
& \text { Total number of needle }=\pi \times \text { Machine diameter } \times \text { Machine gauge } \\
& \text { Total number of stitches produced per hour } \\
& =\text { No. of needle } \times \text { RPM } \times 60 \times \text { No.of feeder } \times \text { efficiency } \\
& \text { Length of yarn converted into stitches per hour } \\
& =\text { Total no. of stitch produced per hour } \times \text { stitch length } \\
& \text { Weight of yarn converted into fabric in lbs } \\
& =\frac{\text { Length of yarn converted into stiches per hour in yards }}{840 \times \text { Yarn count }(\mathrm{Ne})}
\end{aligned}
$$

So the formula of production will be,

$$
\begin{aligned}
& \text { Production per hour in lbs } \\
& =\frac{\pi \times \text { Machine dia } \times \text { Gauge } \times \text { RPM } \times \text { No. of feeder } \times \text { Stitch length }(\text { inch }) \times \text { Efficiency }}{840 \times \text { Yarn count }(\mathrm{Ne}) \times 36}
\end{aligned}
$$


For $2 \times 1$ rib fabric: In $2 \times 1$ rib machines one needle is dropped after every two needles so that two third of total needles are active in the machine.

Production per hour in lbs

$$
=\frac{\pi \times \text { Machine dia } \times \text { Gauge } \times \frac{2}{3} \times \text { RPM } \times \text { No. of feeder } \times \text { Stitch length }(\text { inch }) \times \text { Efficiency }}{840 \times \text { Yarn } \operatorname{count}(\mathrm{Ne}) \times 36}
$$

For $2 \times 2$ rib fabric: During machine setting of $2 \times 2$ ribs gating two needles are dropped after every two needle. So t hat, two fourth or half of total needles are active.

Production per hour in lbs

$$
=\frac{\pi \times \text { Machine dia } \times \text { Gauge } \times \frac{1}{2} \times \text { RPM } \times \text { No. of feeder } \times \text { Stitch length }(\text { inch }) \times \text { Efficiency }}{840 \times \text { Yarn } \operatorname{count}(\mathrm{Ne}) \times 36}
$$

For $3 \times 2$ rib fabric: In $3 \times 2$ rib gating two needles are dropped after every three needle so that three fifth of total needles are active and rest are inactive.

Production per hour in lbs

$$
=\frac{\pi \times \text { Machine dia } \times \text { Gauge } \times \frac{3}{5} \times \text { RPM } \times \text { No. of feeder } \times \text { Stitch length }(\text { inch }) \times \text { Efficiency }}{840 \times \text { Yarn count }(\mathrm{Ne}) \times 36}
$$

For $3 \times 3$ rib fabric: Three needles are dropped after every three needle for $3 \times 3$ rib gating. So that three sixth or half of total needles are active in the machine.

Production per hour in lbs

$$
=\frac{\pi \times \text { Machine dia } \times \text { Gauge } \times \frac{1}{2} \times \text { RPM } \times \text { No. of feeder } \times \text { Stitch length }(\text { inch }) \times \text { Efficiency }}{840 \times \text { Yarn } \operatorname{count}(\mathrm{Ne}) \times 36}
$$

For $4 \times 1$ rib fabric: During the time of $4 \times 1$ rib machine setting one needle is dropped after every four needle. So that four fifth of total needles are active.

Production per hour in lbs

$$
=\frac{\pi \times \text { Machine dia } \times \text { Gauge } \times \frac{4}{5} \times \text { RPM } \times \text { No. of feeder } \times \text { Stitch length }(\text { inch }) \times \text { Efficiency }}{840 \times \text { Yarn } \operatorname{count}(\mathrm{Ne}) \times 36}
$$

For $4 \times 4$ rib fabric: For $4 \times 4$ rib fabric machine setting, four needles are dropped after every four needles. So, half of total needles are active in the machine.

Production per hour in lbs

$$
=\frac{\pi \times \text { Machine dia } \times \text { Gauge } \times \frac{1}{2} \times \text { RPM } \times \text { No. of feeder } \times \text { Stitch length }(\text { inch }) \times \text { Efficiency }}{840 \times \text { Yarn } \operatorname{count}(\mathrm{Ne}) \times 36}
$$

For $\boldsymbol{x} \times \boldsymbol{y}$ rib fabric: For $x \times y$ rib fabric machine setting, $y$ no. of needles is dropped after every $x$ no. of needles. So, $x$ off $1 / x+y$ No. needles is active and rest is inactive.

Production per hour in lbs

$$
=\frac{\pi \times \text { Machine dia } \times \text { Gauge } \times \frac{x}{x+y} \times \text { RPM } \times \text { No. of feeder } \times \text { Stitch length }(\text { inch }) \times \text { Efficiency }}{840 \times \text { Yarn } \operatorname{count}(\mathrm{Ne}) \times 36}
$$

For $1 \times 1$ interlock machine: During interlock fabric production at a time fifty percent needles are active and rest fifty percent are inactive. There is no need to drop any needle for $1 \times 1$ interlock fabric. 
Production per hour in lbs

$$
=\frac{\pi \times \text { Machine dia } \times \text { Gauge } \times \frac{1}{2} \times \text { RPM } \times \text { No. of feeder } \times \text { Stitch length }(\text { inch }) \times \text { Efficiency }}{840 \times \text { Yarn } \operatorname{count}(\mathrm{Ne}) \times 36}
$$

For $2 \times 2$ interlock fabric: For the machine setting of $2 \times 2$ interlock fabric 2 needles are needed to drop after every two needle from both of the bed. For this reason half of total needles are present in the machine and acting as working needle. Again fifty percent or half of total present needles are working at a time.

$$
=\frac{\pi \times \text { Machine dia } \times \text { Gauge } \times \frac{1}{2} \times \frac{1}{2} \times \text { RPM } \times \text { No. of feeder } \times \text { Stitch length }(\text { inch }) \times \text { Efficiency }}{840 \times \text { Yarn } \operatorname{count}(\mathrm{Ne}) \times 36}
$$

For $\boldsymbol{x} \times \boldsymbol{y}$ interlock fabric: For $x \times y$ interlock fabric machine setting, $y$ no. of needles is dropped after every $x$ No. of needles from both of the needle bed. So, $x$ off $1 / x+y$ No. needles is active and rest is inactive. In one knitting cycle fifty percent of total active needles are working. In second knitting cycle rest fifty percent needles are working. So, in every knitting cycle fifty percent of total active needles are working.

Production per hour in $\mathrm{lb}$

$$
=\frac{\pi \times \text { Machine dia } \times \text { Gauge } \times \frac{x}{x+y} \times \frac{1}{2} \times \text { No. of feeder } \times \text { Stitch length }(\text { inch }) \times \text { Efficiency }}{840 \times \text { Yarn count }(\mathrm{Ne}) \times 36}
$$

No. of active needles present in the machine directly influence the production per hour of knitting machine. Increasing the No. of active needle in the machine increases the production of this machine. According to this and also according to the formula $1 \times 1$ interlock fabric production is half of $1 \times 1$ rib production. But in practically $1 \times 1$ interlock fabric productions are slightly decreases than $1 \times 1$ rib fabric. Because in case of interlock fabric production higher machine speed (RPM) than rib fabric can be achieve. Machine speed (RPM) depend on various factors such as type of fabric, fabric quality, yarn quality, machine condition etc. If RPM are constant for all types of fabric than production are decreases with the design variability of fabric.

\section{Conclusion}

Machine gauge is an important factor for any particular structure and also for calculation of production. Appropriate approach of machine gauge may need to be use for calculation of production mathematically. The values which are used in the production calculation have influences on the production of knit fabric. On the other hand, yarn quality and fabric quality also influenced the knit fabric production. All the values can be constant without total No. of active needle present in the machine. If design of fabric needed to be changed, No. of needles must be dropped and production fabric decreases. Production of fabric has directly influenced the cost of fabric. Higher the fabric production means lower of cost and vice versa. In those cases, cost of fabric will be changed with the design variability of fabric such as $2 \times 1,2 \times 2$, $3 \times 1$ etc. Knitting price per kg also changed as production per hour decreases. However, it is important for the knitter to calculate the production per hour in weight to deliver the products according to buyers lead time. Knitting charge also depends on the production of fabric. Lower the production means per kg production takes higher time. So, knitting charge will be changed as the changing of production per hour. This paper helps to give a new thinking about machine gauge of a knitting machine. By this paper, knitted fabric production in weight can be calculated easily. Although knitted fabric production can be calculated in length but knitted fabric is sold in market by means of weight. So calculation of knitted fabric production in weight is most important for the knitter and also for the person who are related to this sector.

\section{Acknowledgements}

The author thanks to Mr. Abul Kalam Azad, Technical Knitting Manager, AST Knitwear Ltd., Gazipur, Ban- 
gladesh for his technical support and allow the author in the industry.

\section{References}

[1] Ray, S.C. (2011) Fundamentals and Advances in Knitting Technology. Woodhead Publishing India Pvt. Limited, New Delhi.

[2] Belal, E.S.A. (2006) Understanding Textile for a Merchandiser. BMN Publication, Dhaka.

[3] Spancer, D.J. (2001) Knitting Technology. Woodhead Publishing Limited, Cambridge.

[4] Fazley, B.D. (2011) Calculation of Weft Knitting, 2011. http://www.scribd.com/doc/52320541/Calculation-in-Weft-Knitting\#scribd (Accessed 13 December 2016)

[5] Systems of the Basic Weft Knitted Machine (2012). http://nptel.ac.in/courses/116102008/9 (Accessed 13 December 2016) 